The Journal of

Thoracic and Cardiovascular

Surgery

Vol 130, No. 6, December 2005

\title{
They're here: Continuing medical education activities
}

\author{
Andrew S. Wechsler, MD, and Pamela W. Fried
}

From Drexel University College of Medicine, Philadelphia, $\mathrm{Pa}$

Received for publication Oct 17, 2005; accepted for publication Oct 17, 2005.

Address for reprints: Pamela W. Fried, Drexel University College of Medicine, 245 North 15th St, Room 6415, Philadelphia, PA 19102-1192 (E-mail: pfried@drexelmed. edu).

J Thorac Cardiovasc Surg 2005;130:1491

$0022-5223 / \$ 30.00$

Copyright $(02005$ by The American Association for Thoracic Surgery

doi:10.1016/j.jtcvs.2005.10.009
$\mathrm{W}$

e have long believed that journals are a rich source for the continuance of learning that is critical for safe, innovative clinical practice. This belief is one of the reasons that articles submitted to The Journal of Thoracic and Cardiovascular Surgery (JTCVS) are subject to such stringent peer review. Articles that appear in print one day may well form the basis for practice the next. Although being a knowledgeable and contemporary surgeon should be reward enough for the hours spent digesting new information, various certifying and privileging entities require documentation of such efforts.

Thus, we are particularly pleased that, through the auspices of the American Association for Thoracic Surgery, beginning with this issue of the Journal, it will be possible for JTCVS subscribers to acquire continuing medical education (CME) credits for thoughtful reading of selected published articles. The authors of these selected articles have accepted the additional burden of creating questions designed to evaluate the learner's understanding of the content of their articles in such a way as to make them acceptable for CME credit. We think learners will enjoy the short tests and benefit from the accrued credits.

The CME activities are accessible to all JTCVS subscribers via several paths:

1. Direct access to the CME Web site home page using the url http://cme. ctsnetjournals.org. From the CME home page, choose JTCVS. The next screen lists 3 general subject areas: surgery for acquired cardiovascular disease, general thoracic surgery, and surgery for congenital heart disease. Behind each subject area is a list of CME activities. Note, however, that the December issue, being the introductory issue, will contain just one article per category. Each month, another article will be added in each category. Articles will be available on the site for 2 years.

2. Direct access to an activity from the Journal table of contents. Click on the CME designation link next to the title of the CME article in the table of contents. The link will take the learner directly to the "take this course" screen.

3. Direct access to an activity from within the CME-designated article: In the section of the article-information box called "This Article," click the CME link.

4. Indirect access via the print version of the Journal: CME articles will be designated with an appropriate icon both in the table of contents and on the article title page and Web site access information will be provided.

This project has been a collaborative effort between CTSNet, the Annals of Thoracic Surgery, The Journal of Thoracic and Cardiovascular Surgery, and the European Journal of Cardio-Thoracic Surgery. The effort was led by L. Henry Edmunds, Jr, Editor, Annals of Thoracic Surgery, who helped the group construct exercises in keeping with the complicated rules behind the CME process and kept after the editors and managing editors until they got it right. The entire group extends thanks to Dr Edmunds for his perseverance and wisdom. Thanks also to Peter Green, Executive Editor, CTSNet, and Polly Siegel, Journal Manager, Highwire Press, who served as referees, peacekeepers, coordinators, and occasionally as enforcers for the project. The work done by Heide Pustzy, Managing Editor, Annals of Thoracic Surgery, in coordinating preparation of complicated content documents is also gratefully acknowledged. 